\title{
Assessing satellite-based precipitation estimates in the Southern Appalachian mountains using rain gauges and TRMM PR
}

\author{
O. P. Prat and A. P. Barros \\ Civil and Environmental Engineering Department, Pratt School of Engineering Duke University, Durham NC 27708, USA
}

Received: 19 December 2009 - Revised: 6 May 2010 - Accepted: 6 May 2010 - Published: 8 June 2010

\begin{abstract}
A study was performed using the first full year of rain gauge records from a newly deployed network in the Southern Appalachian mountains. This is a region characterized by complex topography with orographic rainfall enhancement up to $300 \%$ over small distances $(<8 \mathrm{~km})$. Rain gauge observations were used to assess precipitation estimates from the Precipitation Radar (PR) on board of the TRMM satellite, specifically the TRMM PR 2A25 precipitation product. Results show substantial differences between annual records and isolated events (e.g. tropical storm Fay). An overall bias of $-27 \%$ was found between TRMM PR 2A25 rain rate and rain gauge rain rates for the complete one year of study ( $-59 \%$ for tropical storm Fay). Besides differences observed for concurrent observations by the satellite and the rain gauges, a large number of rainfall events is detected independently by either one of the observing systems alone (rain gauges: $50 \%$ of events are missed by TRMM PR; TRMM PR: $20 \%$ of events are not detected by the rain gauges), especially for light rainfall conditions $(0.1-2 \mathrm{~mm} / \mathrm{h})$ that account for more than $80 \%$ of all the missed satellite events. An exploratory investigation using a microphysical model along with TRMM reflectivity factors at selected heights was conducted to determine the shape of the drop size distribution (DSD) that can be applied to reduce the difference between TRMM estimates and rain gauge observations. The results suggest that the critical DSD parameter is the number concentration of very small drops. For tropical storm Fay an increase of one order of magnitude in the number of small drops is apparently needed to capture the observed rainfall rate regardless of the value of the measured reflectivity. This is consistent with DSD observations that report high concentrations of small and/or midsize drops in the case of tropical storms.
\end{abstract}

Correspondence to: O. P. Prat (oprat@duke.edu)

\section{Introduction}

The TRMM (Tropical Rainfall Measuring Mission) was launched in 1997 in order to provide precipitation measurements between latitudes $40^{\circ} \mathrm{S}-40^{\circ} \mathrm{N}$ with a revisiting time of one day on average. Since the beginning of the mission, significant efforts were directed toward ground validation (GV) of TRMM science products (e.g., Robinson et al., 2000; Wolff et al., 2005; Amitai et al., 2006; Marks et al., 2009; Franchitto et al., 2009, among others) and several studies provided a comparison of TRMM satellite data with rain gauge observations for various parts of the globe (recently Lamptey 2008; Zhou et al., 2008; Vila et al., 2009). However, only a limited body of studies is available for satellite precipitation estimates in mountainous regions where satellite-based products tend to severely underestimate rainfall at higher elevations (Barros et al., 2000; Lang and Barros 2002; Barros and Tao, 2008). Therefore, there is a pressing need for ground based measurements in order to better understand the underlying microphysical and dynamical precipitation processes, and to improve retrieval algorithms. In this context, the region of the Southern Appalachians provides a unique setting to study both warm and cold season orographic precipitation regimes (Prat and Barros, 2009a). For that purpose a high resolution ground observating system consisting of 33 rain gauges (RG) was deployed in the inner region of the Southern Appalachians starting in spring 2007. Rain gauges were installed at mid to high elevations along exposed ridges and in remote areas where no measurements had ever been made. Previous studies focused on the detailed analysis of deployments of vertically pointing radars to investigate the seasonality of microphysical properties of precipitation (Prat and Barros, 2009a). In this work we use one year $(06 / 01 / 08$ to $05 / 15 / 09)$ rain gauge observations (20 rain gauges in operation for this period) to assess TRMM PR precipitation estimates in order to quantify differences between ground based and remotely sensed land observations

Published by Copernicus Publications on behalf of the European Geosciences Union. 


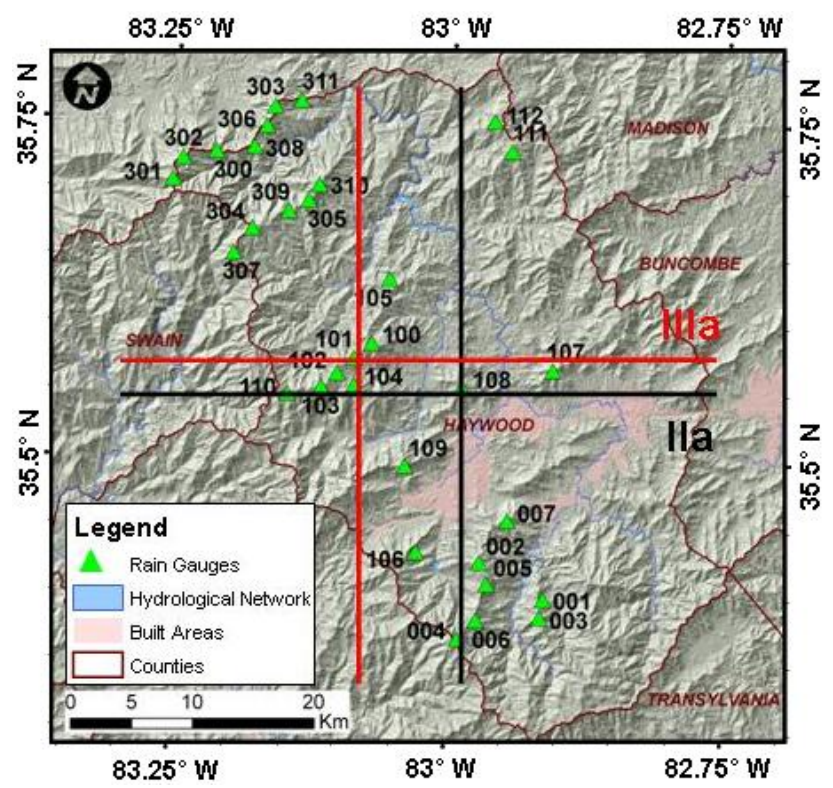

Fig. 1. Locations of the rain gauges constituting the GSMNP network in Haywood County, NC. Rain gauges numbered OXX and $1 \mathrm{XX}$ are used in this study. Rain gauges numbered $3 \mathrm{XX}$ installed in summer 2009 are only here for representative purposes and are not included in the present study. Figure is adapted from Prat and Barros, 2009a.

at the time of the satellite overpass. In addition observations from tropical storm Fay that crossed the area in August 2008 will be analyzed separately as a case study. The paper is organized as follows: First we provide a brief description of the datasets used in this study. Second, the rain gauge observations are used to quantify the spatial and the seasonal variability of precipitation. Third a comparison of TRMM precipitation estimates and rain gauge observations are presented. Finally, a microphysical model (Prat and Barros, $2007 \mathrm{a}, \mathrm{b}$ ) is used to derive surface rain rate intensities from TRMM reflectivity measurements and microphysical implications are discussed.

\section{Input datasets}

\subsection{The Great Smoky Mountain National Park (GSMNP) rain gauge network}

The GSMNP rain gauge network includes 33 rain gauges deployed at mid to high elevations (from $1150 \mathrm{~m}$ to $1920 \mathrm{~m}$ ) along exposed ridges (Fig. 1). The network is deployed in the Western part of the state of North Carolina (USA) in the Southern Appalachians in areas where no previous rainfall observations were ever made, and complement existing observations available at low elevations. In this work, we focus on the data collected by a group of 20 rain gauges installed in the summer 2007 (RG0XX: Fig. 1) and summer 2008
(RG1XX: Fig. 1). Data from rain gauges installed in summer 2009 (RG3XX: Fig. 1) are not yet available. The tipping bucket rain gauges used are the model TB3 (RG0XX: catchment size of $200 \mathrm{~mm} ; 0.2 \mathrm{~mm} / \mathrm{tip}$ ) and TB3/0.1 (RG1XX: catchment size of $282.8 \mathrm{~mm} ; 0.1 \mathrm{~mm} / \mathrm{tip}$ ). Each rain gauge is visited approximately every two-three months for regular maintenance and data collection. Quality control of collected data is performed for each rain gauge and any doubtful data were not considered in this study. More details on the GSMNP rain gauge network can be found in Prat and Barros, 2009a.

\subsection{TRMM PR 2A25 products}

Data used here for the cross-comparison between ground based rain gauge records and remotely sensed rainfall estimates comprise nearly one year of data from 06/01/08 to 05/15/09 from the TRMM PR (Precipitation Radar), specifically the 2A25 products (http://disc.sci.gsfc.nasa.gov/precipitation/documentation/ TRMM_README/TRMM_2A25_readme.shtml/). Briefly, the TRMM PR scanning radar operates at $13.8 \mathrm{GHz}$ and provides an instantaneous estimate of the 3-D rainfall distribution at the location the satellite overpass. The TRMM PR algorithm 2A25 uses a hybrid of the surface method and the Hitschfeld-Bordan method to correct from the rain attenuation of the measured reflectivity (Iguchi et al., 2000). Each overpass covers a $247 \mathrm{~km}$ wide band, and an independent estimate of the rain rate is provided for each beam (horizontal resolution: $0.045^{\circ} \times 0.045^{\circ}$; vertical resolution: $250 \mathrm{~m}$ and up to $20 \mathrm{~km}$ ). The TRMM $2 \mathrm{~A} 25$ product includes the estimated rain rate at the actual surface (hereafter EstSurfRR) and the rain rate near the surface (hereafter NearSurfRR) which is the estimate at the lowest point non affected by the mainlobe clutter. In addition, TRMM 2A25 provides averaged values of the rain rate for each ray between the predefined heights of 2- and 4-km (hereafter Avg 2 to $4 \mathrm{~km}$ ) and for the entire atmospheric column from top to bottom of the rainshaft (hereafter Avg Column). More details on the TRMM PR 2A25 algorithm itself can be found in Iguchi et al. (2000) and Meneghini et al. (2000).

\section{Observations of the mountainous precipitation with the GSMNP rain gauge network}

Figure 2 displays the daily average rain rate recorded at the 20 locations in this study. Daily rain accumulations are computed over rainy and non-rainy days indistinctly and days when the rain gauges were not in use due to operational problems were removed from the records. Except for two rain gauges (RG111 and RG006), the differences in terms of operational duration for all rain gauges of both rain gauge network (RG0XX-RG1XX) were within 10\%. An 

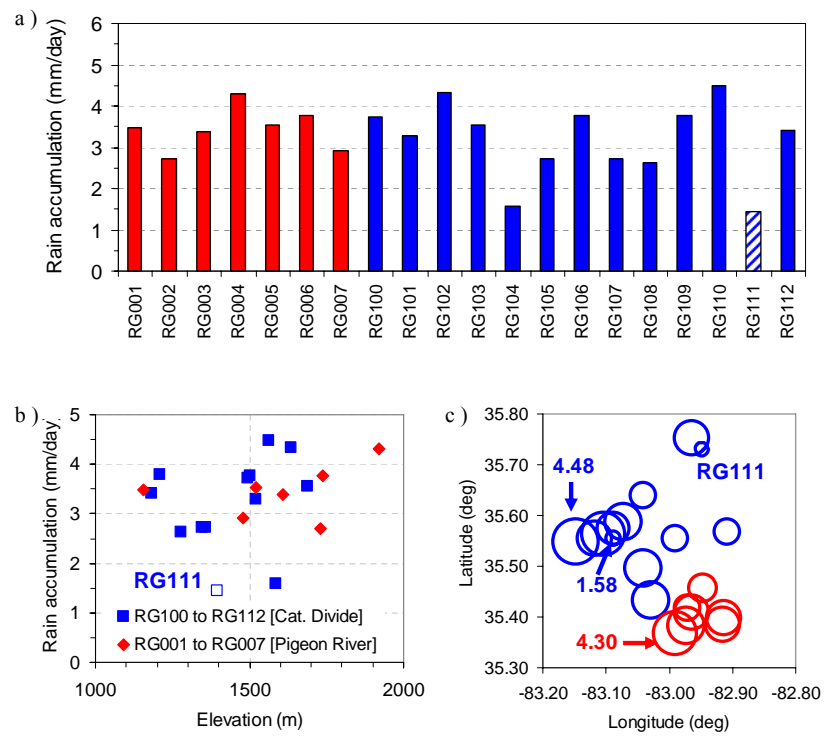

Fig. 2. (a) Average rain accumulation ( $\mathrm{mm} /$ day) for the rain gauges deployed in the GSMNP. Average rain accumulation as a function of: (b) Elevation. (c) Geolocation of each rain gauge. The size of the symbols represents the average daily rain accumulation (mm/day).

average of $3.2 \mathrm{~mm} /$ day is recorded for the 20 rain gauges with a maximum of $4.48 \mathrm{~mm} /$ day (RG110) and a minimum of $1.44 \mathrm{~mm} /$ day (RG104) (Fig. 2a). Considering that all rain gauges used in this study (RG0XX-RG1XX) are located within a $20 \mathrm{~km}$ radius (Fig. 1), note the variation up to $300 \%$ in daily accumulations. This spatial-difference is more dramatic due to the fact that this 3 -fold increase is observed within the six rain gauges located along the Cataloochee divide ridge (RG100-101-102-103-104-110) which are separated by less than $8 \mathrm{~km}$. Comparatively, this difference is only in the order of $60 \%$ for the seven rain gauges RG0XX also separated by a comparable distance of $8 \mathrm{~km}$ but on the inner (second) ridge with regard to the eastern slopes of the Appalachians (Fig. 1). Rain gauge RG111 was out of use and is not included in this comparison, but it was operational during the passage of tropical storm Fay described in the next section. Regardless of RG104 (significant lower daily average rain rate) and RG111 (shorter deployment duration), the data in Fig. 2b suggest orographic enhancement with elevation, which is however modulated by 3-D landform effects. A more consistent pattern is observed when accumulation is displayed as a function of the spatial location (Fig. 2c) with shows increasing accumulation not only with elevation but also with latitude, specifically latitude increments in the NE direction consistent with the propagation of SWesterly events perpendicularly to the alignment of the mountain ridges (Fig. 1).

Figure 3 displays the three-hourly diurnal cycle for each network: Pigeon River Basin (RG0XX), Cataloochee Divide (RG1XX), and the average for all rain gauges as a
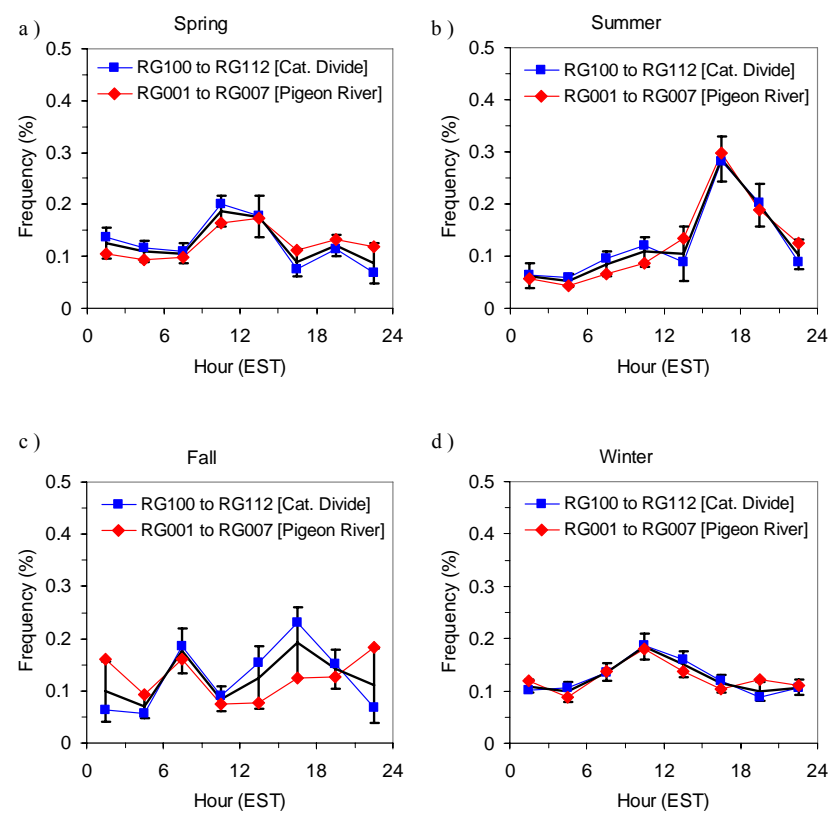

Fig. 3. Three-hourly diurnal cycle as a function of the meteorological season of the year and the rain gauge network location (Pigeon River basin and Cataloochee Divide): (a) spring (Mar-Apr-May), (b) summer (Jun-Jul-Aug), (c) Fall (Sep-Oct-Nov), (d) winter (Dec-Jan-Feb).

function of the season of the year: spring (Mar-Apr-May: Fig. 3a), summer (Jun-Jul-Aug: Fig. 3b), Fall (Sep-OctNov: Fig. 3c), and winter (Dec-Jan-Feb: Fig. 3d). There is a relatively good agreement for the diurnal cycle for the two main areas of rain gauge deployment (Pigeon River bassin and Cataloochee divide). Between seasons, the most noticeable difference is observed for the summertime diurnal cycle, with about $40 \%$ for the frequency of rain events occurring in afternoon/late afternoon (1500-2100EST) (Fig. 3b). The diurnal cycles for spring (Fig. 3a) and fall (Fig. 3c) are more homogenous throughout the day with less than $20 \%$ of all events taking place in any three-hourly period. During spring, two small maxima are found in the morning (around 1200EST) and late afternoon/early evening (1800-2100EST) (Fig. 3a). Fall is the season for which the higher variability is observed between the two ridges (Fig. 3c). In addition, a clear transition from a summer regime with predominant late afternoon thunderstorm orographic activity to a more homogenous fall regime is apparent only in the Pigeon River basin rain gauge network (RG0XX). Finally, fall records should be analyzed with caution due to the possible sporadic presence of snow in the rain gauge funnel. The same comment applies for the winter diurnal cycle that displays a bell shaped curve with maximum located around 1200EST, when insolation is maximum (Fig. 3d), thus suggesting that melting of snow in the funnel may be taking place. 
Table 1. Contingency table for TRMM 2A25 surface rain rate and 10 -min rain gauge rain rates. The 10 -min time scale is centered over the time the satellite overpasses.

\begin{tabular}{|c|c|c|c|c|}
\hline & \multicolumn{4}{|c|}{ All rain gauges ( $0 \mathrm{XX}$ and $1 \mathrm{XX})$} \\
\hline 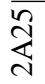 & & Yes & No & Tot. \\
\hline $\bar{\Omega}$ & Yes & 271 & 180 & 451 \\
\hline$\sum$ & No & 448 & 12967 & 13415 \\
\hline 品 & Tot. & 719 & 13147 & 13866 \\
\hline
\end{tabular}

\section{Multisensor intercomparison: ground based measurements versus remotely sensed rain rate estimates}

\subsection{RG/TRMM PR 2A25 difference statistics}

For the period of study (06/01/08 to $05 / 15 / 09)$, there was on average one TRMM overpass per day. The area where the 20 rain gauges used in this study are installed corresponds approximately to a radius of $20 \mathrm{~km}$ centered over RG108 (Fig. 1). From this total of 356 TRMM overpasses, about $36 \%$ (131) overpasses registered concurrent rain at one (or several) of the 20 rain gauge locations and for the TRMM PR 2A25 retrieved surface rain rate. For about 13\% (45) overpasses, rainfall was recorded at the gauges but the TRMM PR 2A25 retrieved rain rate is null. The opposite was found for only $3 \%$ (10) overpasses, with TRMM PR 2A25 surface rain rate non-null but no rainfall detected by the rain gauges. Finally, about $8 \%$ (28) overpasses had rain simultaneously measured at the ground (at one or several rain gauge locations) and retrieved by TRMM PR 2A25 (at one or several corresponding rain gauge locations). Table 1 summarizes the contingency table for the period of study. The number of rain events detected simultaneously by the rain gauge and TRMM PR is lower (271) than the number of events observed by the rain gauge and not detected by the PR (448), but higher than the number of events observed by the PR and not recorded by the corresponding rain gauge (180). Although the definition of rain event from a TRMM PR perspective is straightforward (i.e. non-null value retrieved for the rain intensities EstSurfRR and NearSurfRR), from a rain gauge point of view two conditions are imposed. First at least two tips have to be recorded within one hour centered at the time the satellite overpass to qualify as a rain event. This corresponds to a minimum cumulative rain amount of $0.4 \mathrm{~mm}$ (for the Pigeon River Bassin network using rain gauge TB3: RG0XX) or $0.2 \mathrm{~mm}$ (for the Cataloochee divide network using rain gauge TB3-0.1 mm: RG1XX). This allows accounting for light rainfall events (i.e. $0.2 \mathrm{~mm} / \mathrm{h}$ and $0.4 \mathrm{~mm} / \mathrm{h}$ ), while removing the presence of accidental tips. A sensitivity study was performed on a range of time-windows (from $6 \mathrm{~min}$ to $1 \mathrm{~h}$ ) centered on the time of TRMM overpass, and no significant differences were observed in the performance parameters reported in Table 2. Rather than a temporal window effect, results display noticeable differences depending on which ridge the rain gauges are installed with better overall performance for the network RG1XX (inner ridge) than RG0XX (outer ridge) (Table 2). Figure 4 displays the comparison of TRMM PR 2A25 retrieved rain rates against averaged gauge rates. For all records (Fig. 4a: TRMM PR 2A25 and/or RG records non-null) the slope is less than unity for both the near surface rain rate $(0.73)$ and the estimated surface rain rate (0.82). Despite a larger number of null TRMM records/non null RG records (448) when compared to non-null TRMM records/null RG records (180), this result is influenced by the higher rain rate average $(\mathrm{RR}=1.7 \mathrm{~mm} / \mathrm{h})$ in the case nonnull TRMM records/null RG records than for null TRMM records/non null $R G$ records $(R R=1.1 \mathrm{~mm} / \mathrm{h})$. Considering simultaneously non-null TRMM/RG records (Fig. 4b); a higher slope is obtained with 1.06 and 1.19 for the near surface and the estimated surface rain rate respectively. For simultaneously non-null TRMM/RG records, the bias between TRMM PR 2A25 rain rate estimates and surface rain rates measured by the rain gauges measured rain rates is computed according to:

$\operatorname{Bias}(\%)=\sum_{i=1}^{N}\left(\mathrm{RR}_{\mathrm{TRMM}}-\mathrm{RR}_{\mathrm{RG}}\right) / \sum_{i=1}^{N} \mathrm{RR}_{\mathrm{RG}}$

In order to account for eventual errors introduced in the estimation of the surface rain rate from rain gauge records (Wang et al., 2008), the sensitivity to the rain gauge time averaging was examined against various TRMM PR 2A25 rain rate estimates: i.e. near surface rain rate, estimated surface rain rate, averaged rain rate between the predefined heights of 2- and 4-km, and averaged rain rate for the whole atmospheric column (Fig. 4c). Results display different bias for different TRMM PR products: near surface rain rate (NearSurfRR), estimated surface rain rate (EstSurfRR), 2-4 km averaged rain rate (Avg 2 to $4 \mathrm{~km}$ ) and column averaged rain rate (Avg Column), all biases being negative. Regardless of the TRMM PR product, we note that the bias presents a minimum for a $7 \mathrm{~min}$ averaging period and is relatively stable for 10 - and 60 -min rain rates. A 10 -min rain rate (centered over the time of overpass) provides a good compromise between TRMM and rain gauge representativeness. Furthermore, a 10-min rain rate allows explicit consideration of the two different tip volumes of the rain gauges corresponding with $0.1 \mathrm{~mm}$ and $0.2 \mathrm{~mm}$ for networks RG1XX and RG0XX respectively. Longer time-scales for rain rate computations (above 4-min) tend to reduce error estimates especially for low rain rates (Wang et al. 2008). Note that the selection of a 10-min rain rate is not necessarily reflected by the overall performance of the rain gauge network (Table 2) mainly due to the high number of concurrent null TRMM/RG records (Table 1). As TRMM/RG timing issues have been ruled out 
Table 2. TRMM 2A25/RG performance comparison as a function of the time scale (7-, 10-, 20-, 30-min). Definition of performance parameters is reported below.

\begin{tabular}{|c|c|c|c|c|c|c|c|c|c|c|c|c|c|}
\hline \multicolumn{14}{|c|}{ Time window (min) } \\
\hline & \multicolumn{3}{|c|}{$7 \min$} & \multicolumn{3}{|c|}{$10 \mathrm{~min}$} & \multicolumn{3}{|c|}{$20 \mathrm{~min}$} & \multicolumn{3}{|c|}{ 30min } & \multirow{2}{*}{$\begin{array}{l}\text { Perfect } \\
\text { Score }\end{array}$} \\
\hline & All & $0 \mathrm{XX}$ & $1 \mathrm{XX}$ & All & $0 X X$ & $1 \mathrm{XX}$ & All & $0 X X$ & $1 \mathrm{XX}$ & All & $0 \mathrm{XX}$ & $1 \mathrm{XX}$ & \\
\hline Accuracy ${ }^{1}$ & 0.96 & 0.95 & 0.96 & 0.95 & 0.95 & 0.96 & 0.95 & 0.95 & 0.95 & 0.95 & 0.95 & 0.95 & 1 \\
\hline $\mathrm{FB}^{2}$ & 0.65 & 0.74 & 0.59 & 0.63 & 0.72 & 0.57 & 0.58 & 0.67 & 0.53 & 0.53 & 0.62 & 0.48 & 1 \\
\hline $\mathrm{POD}^{3}$ & 0.38 & 0.38 & 0.38 & 0.38 & 0.39 & 0.37 & 0.37 & 0.38 & 0.36 & 0.35 & 0.37 & 0.34 & 1 \\
\hline FAR $^{4}$ & 0.41 & 0.48 & 0.36 & 0.40 & 0.46 & 0.35 & 0.37 & 0.44 & 0.31 & 0.34 & 0.40 & 0.30 & 0 \\
\hline POFD $^{5}$ & 0.01 & 0.02 & 0.01 & 0.01 & 0.02 & 0.01 & 0.01 & 0.02 & 0.01 & 0.01 & 0.01 & 0.01 & 0 \\
\hline $\mathrm{TS}^{6}$ & 0.30 & 0.28 & 0.31 & 0.30 & 0.29 & 0.31 & 0.30 & 0.29 & 0.31 & 0.30 & 0.30 & 0.29 & 1 \\
\hline
\end{tabular}

${ }^{1}$ Accuracy $=[\mathrm{YY}+\mathrm{NN}] /$ Total $^{2}$ Frequency Bias=FB=[YY+YN]/[YY+NY ${ }^{3}$ Probability of detection=POD=YY/[YY+YN $]$

${ }^{4}$ False alarm ratio=FAR=NY/[YY+NY $]{ }^{5}$ Probability of False Detection=POFD=NY/[NN+NY $]{ }^{6}$ Threat $\mathrm{Score}=\mathrm{TS}=\mathrm{YY} /[\mathrm{YY}+\mathrm{NY}+\mathrm{YN}]$

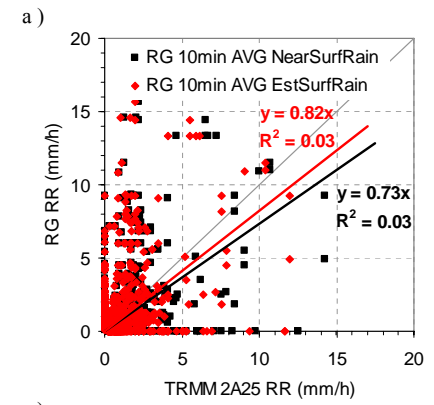

c )
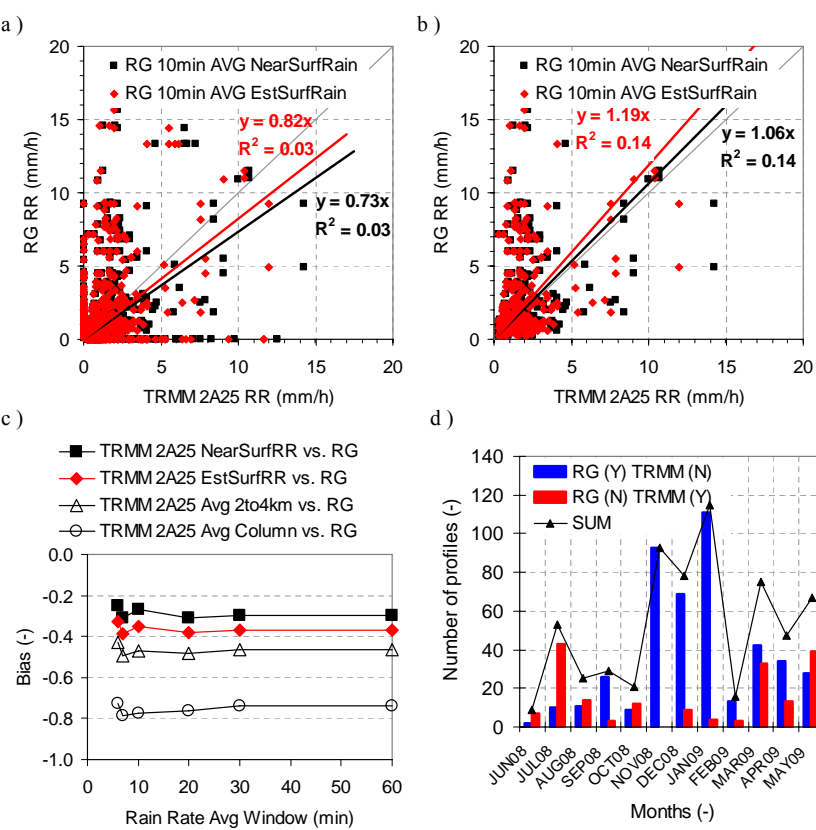

d)

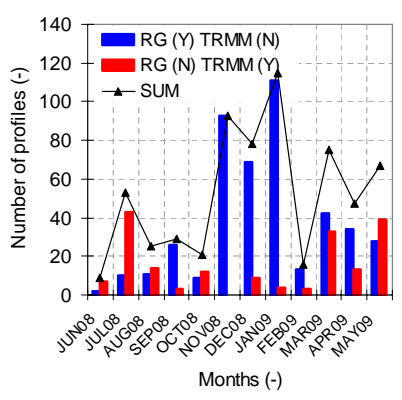

Fig. 4. Scatterplots for the comparison TRMM $2 \mathrm{~A} 25$ surface rain rate and averaged rain gauge rain rates for the period 06/01/0805/15/09: (a) For all TRMM 2A25 surface rain rates and rain gauges records, (b) For non null TRMM 2A25 surface rain rates and rain gauges records. Rain gauges rain rates are averaged using a 10-min scale centered at the time the satellite overpasses. (c) Bias sensitivity as a function of the TRMM $2 \mathrm{~A} 25$ rain product and rain gauge rain rate scale. (d) Repartition of the number of hits/misses as a function of the month of the year.

by considering an $1 \mathrm{~h}$ time frame centered at the time of overpass, a closer look of the annual repartition of TRMM-RG hits and misses provides two possible explanations (Fig. 4d). First we observe a large proportion of hits-misses for Fallwinter (Nov-Dec-Jan) with nearly only RG hits (i.e. TRMM misses). With snowfall detected as early of October for the period of study 06/01/08-05/15/09 (Prat and Barros, 2009a), this could be explained by the presence of snow or delayed snow melting events that would be alternatively detected by one sensor or the other. We also note a large total number of hits-misses during spring (Mar-Apr-May) and summer (July). One possible explanation could be the occurrence of localized isolated shallow convective events either measured by the rain gauge or retrieved by TRMM but not by both and, or the presence of fog/low level clouds frequent in this area of the GSMNP during spring/summertime. No particular trends were found for the repartition of hits-misses as a function of the hour of the day, but due to the 1-year duration of the study, the sampling may be inadequate to generate strong statistics. However the 3-hourly repartition of hitsmisses for winter (RG-Yes/TRMM-No) indicates that about $50 \%$ occurred during the afternoon and tends to confirm the hypothesis of snowmelt events (a camera located near RG100 reported the presence of snow for those days and a clear sky). Similarly the 3-hourly repartition of hits-misses for summer (RG-No/TRMM-Yes) with about 50\% of TRMM records occurring in the afternoon seems to suggest the presence of localized shallow convective events within the PR pixel but not detected by the rain gauges. The use of ground based radar products could help verifying the existence of clear atmosphere conditions, and if the mismatch is due to a limited rain gauge network performance or TRMM PR sensitivity. However this task might be delicate due the fact that the coverage of the closest radar (NEXRAD: KRMX and KGSP) is strongly affected by mountain blocking (Prat and Barros, 2009a).

Finally, for simultaneously non-null records, the bias for TRMM/RG is about $-27 \%$ for the TRMM $2 \mathrm{~A} 25$ near surface rain rate and $-35 \%$ for the estimated surface rain rate. Please note that the bias is computed for all TRMM/RG concurrent rain records over the entire period of study. For isolated events, such as tropical storm Fay that will be discussed next, the value of the bias can be dramatically different and 


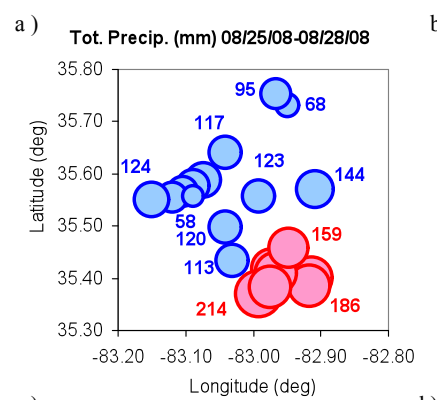

c )
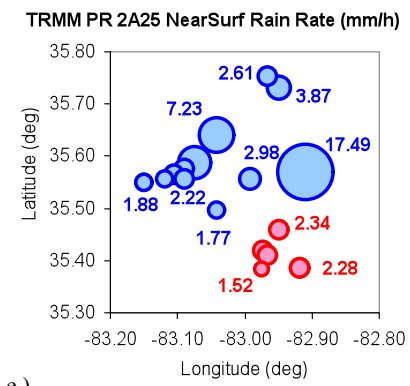

e )

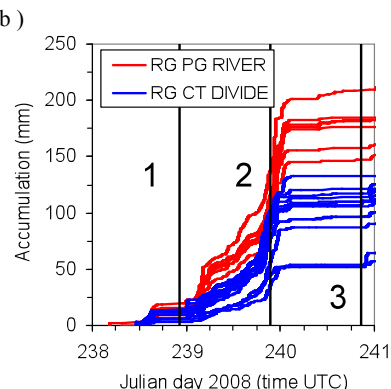

d)

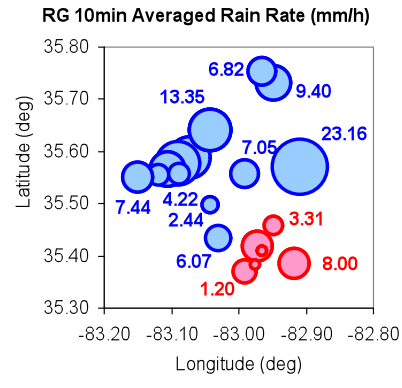

while $109 \mathrm{~mm}(\sigma=23.9 \mathrm{~mm})$ were recorded in the Cataloochee Divide (RG100 to RG112) (Fig. 5a). Three TRMM satellite overpasses $(61409,61424,61439)$ are available for Fay (Fig. 5b). While the first (08/25/08: 61409) and the third (08/27/08: 61439) correspond to no-rain conditions, the second overpass (08/26/08: 61424) coincides with the maximum intensity of the tropical storm (Fig. 5b). TRMM PR 2A25 surface rain rates (Fig. 5c) and 10-min rain rates (Fig. 5d) show the same spatial pattern with maximum rain intensity and shorter duration for rain gauges located along the Chattahoochee Divide ridge (RG100-112), and relatively lower instantaneous intensity and higher duration for the Pigeon River basin rain gauges (RG001-007). Note the contrast with the spatial pattern of cumulative rainfall for Fay (Fig. 5a). In term of TRMM/RG differences, the TRMM PR 2A25 rain rates are systematically lower than those measured locally by the rain gauges with a bias of about $-59 \%$ and $-64 \%$ for the near surface and the estimated surface rain rates respectively (Fig. 5d).

\subsection{Classification of TRMM vertical profiles}

Previous results have pointed out the differences between TRMM estimates and rain gauge measurements either on a long term basis or for more isolated events. In order to understand TRMM/RG differences, TRMM reflectivity and rainfall profiles for the whole year worth of observations were classified into five categories with respect to the TRMM/RG difference (Table 3 ) corresponding to different domains in the RG_RR/TRMM_RR space (Fig. 6a). Regardless of the value of the difference (Table 3), conditions when rain was simultaneously observed by the satellite and rain gauges (cases I, II, III), correspond to approximately $30 \%$ of all cases (899), while about $20 \%$ report rain for TRMM only (case IV) and about $50 \%$ report rain for rain gauges only (case V). TRMM profiles of corrected reflectivity for cases I+II+III display the same characteristics with comparable average reflectivity (Zcorr $\approx 25-30 \mathrm{dBz})$ and standard deviation $\left(\sigma_{\mathrm{Zcorr}} \approx 4\right.$ $6 \mathrm{dBz}$ ) at the lowest elevation just above the ground clutter flag (not shown). The average reflectivity increases with increasing height with maximum frequency (counts) between 2-4 km (not show).

Differences observed between TRMM PR retrieved and rain gauge measured rain-rate for cases I, II, and III, can be explained by the difference of spatial resolution between TRMM PR estimates $\left(0.045^{\circ} \times 0.045^{\circ}\right)$ and rain gauge point measurements. Indeed, depending on the TRMM overpass, the representative area of one TRMM scan $\left(0.045^{\circ} \times 0.045^{\circ}\right)$ encompasses one or several rain gauges due to the fact that some rain gauges are separated by a distance smaller than 4.5 km (RG002/005/006; RG002/007; RG004/006; RG005/006; RG100/101/102/104; RG103/110; RG111/112) (Fig. 1). When one TRMM scan corresponds to several rain gauge measurements, TRMM rain-rate estimates do not reflect the observed spatial variability of rainfall ranging from 
Table 3. Classification of TRMM $2 \mathrm{~A} 25$ reflectivity profiles as a function of the difference $\left[R_{T R} R_{T M}-R_{R G}\right] / R R_{R G}(\%)$.

\begin{tabular}{|c|c|c|c|c|}
\hline \multirow{2}{*}{\multicolumn{2}{|c|}{ Class }} & \multicolumn{3}{|c|}{ Diff $=\left[\mathrm{RR}_{\mathrm{TRMM}}-\mathrm{RR}_{\mathrm{RG}}\right] / \mathrm{RR}_{\mathrm{RG}}(\%)$} \\
\hline & & \multirow{2}{*}{$\begin{array}{l}\varepsilon=0.25 \\
43\end{array}$} & \multirow{2}{*}{$\begin{array}{l}\varepsilon=0.50 \\
95\end{array}$} & \multirow{2}{*}{$\begin{array}{l}\varepsilon=0.75 \\
158\end{array}$} \\
\hline I: & $\operatorname{Abs}($ Diff $)<\varepsilon$ & & & \\
\hline & $\operatorname{Diff}<-\varepsilon$ & 108 & 76 & 28 \\
\hline & $\operatorname{Diff}<-\varepsilon$ and $\mathrm{RR}_{\mathrm{RG}}>7 \mathrm{~mm} / \mathrm{h}$ & 35 & 31 & 20 \\
\hline & Diff $>\varepsilon$ & 120 & 100 & 85 \\
\hline IIIa: & Diff $>\varepsilon$ and $\mathrm{RR}_{\mathrm{TRMM}}>7 \mathrm{~mm} / \mathrm{h}$ & 7 & 7 & 5 \\
\hline & $\mathrm{RR}_{\mathrm{RG}}=0$ and $\mathrm{RR}_{\mathrm{TRMM}} \neq 0$ & 180 & 180 & 180 \\
\hline & $\mathrm{RR}_{\mathrm{RG}} \neq 0$ and $\mathrm{RR}_{\mathrm{TRMM}}=0$ & 448 & 448 & 448 \\
\hline \multirow{2}{*}{\multicolumn{2}{|c|}{$\begin{array}{l}\text { I+II+III [Table 1: YY] } \\
\text { I+II+III+IV+V [Table 1: YY+YN+NY] }\end{array}$}} & 271 & 271 & 271 \\
\hline & & 899 & 899 & 899 \\
\hline
\end{tabular}

$15 \%$ (RG002/003) and up to $200 \%$ (RG100/101/102/104) for daily rates (Fig. 2a). If for the whole period of study $(06 / 01 / 08-05 / 15 / 09)$, we note the relatively low number of events classified as convective (only $1 \%$ (3) of all the records (271) for cases I+II+III), this fraction of convective events for cases IV (i.e. TRMM only) is 7\% (12) of the total (180) and tends to confirm the notion of isolated small-scale convective events in between rain gauges. For the remaining 93\% of events detected by TRMM only (178), these could correspond to dense fog that cannot be detected by the rain gauges, isolated showers that fall in-between rain gauges or TRMM PR false alarms; the latter are very high for low rainfall rate (Barros and Tao, 2008). For cases when only rain gauges report rain (case V), the rain flag for TRMM profiles corresponds unambiguously to no-rain (clear atmosphere) condition for $70 \%$ and "others" for $28 \%$ of the cases (448). The remaining 2\% TRMM profiles are classified as stratiform with low reflectivity factor (Zcorr $\approx 20 \mathrm{dBz}$ ) between the heights of 3-5 km ASL (Fig. 6b).

As mentioned above, no significant differences in TRMM profile characteristics were found for categories I-II-III. However, the two subcategories IIa (Fig. 6c) and IIIa (Fig. 6d) show substantial differences for rain rates above and below $7 \mathrm{~mm} / \mathrm{h}$. Reflectivity profiles corresponding to case IIIa display a sharp increase in reflectivity up to (Zcorr $\approx 40 \mathrm{dBz}$ ) around $3 \mathrm{~km}$ ASL (Fig. 6d). Figure 7a displays the cross sections for tropical storm Fay for a domain encompassing the area of the rain gauge network. The TRMM overpass at about 21:26 UTC on 08/26/08 corresponds approximately to the passage of the tropical storm over the GSMNP rain gauge network (see $\mathrm{E}-\mathrm{W}$ cross sections for $\mathrm{Z}$ and rainrate: Fig. 7a). Cross-sections for reflectivity present a rather uniform profile consistent with large-scale systems and with maximum reflectivity located between $2-3.5 \mathrm{~km}$ ASL. Maximum reflectivity $(Z>35 \mathrm{dBz})$ is found in the longitudinal direction, while peak reflectivity decreases $(\mathrm{Z}<35 \mathrm{~dB}-\mathrm{z})$ with latitude (Fig. 7a) as the storm propagates over the mountains. Along the E-W direction, the TRMM PR rain intensity a)
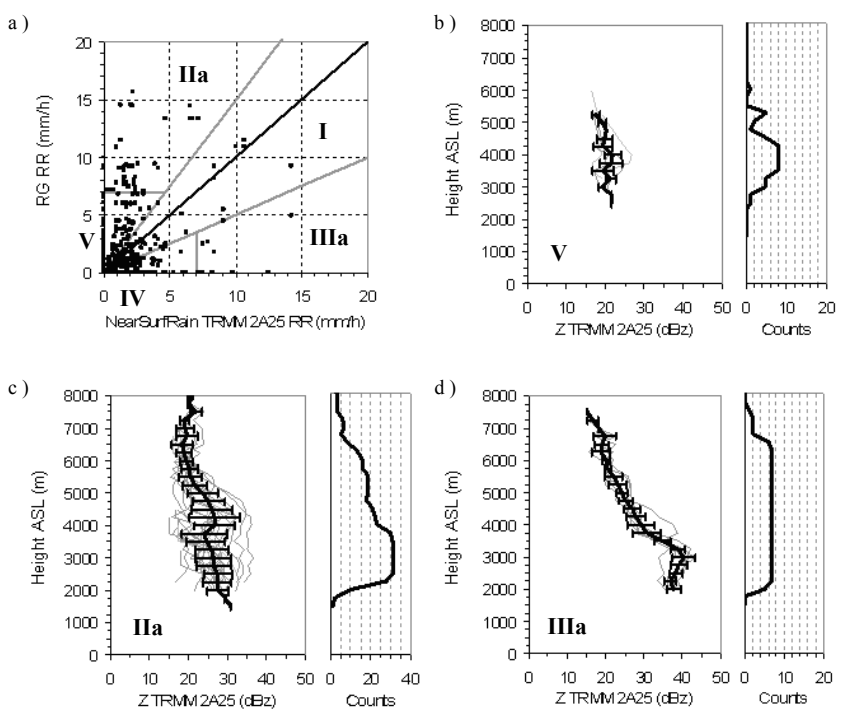

Fig. 6. TRMM $2 \mathrm{~A} 25$ reflectivity profiles. (a) TRMM profiles classification into five categories (I-II-III-IV-V) and 2 subcategories (III-IIIa). Selected TRMM profiles: (b) V (448). (c) IIa (31). (d) IIIa (7).

ranges over a wider range (1- to $40-\mathrm{mm} / \mathrm{h}$ ) than that registered by the rain gauges (Fig. 4e), and yet comparable average rain rates were recorded among rain gauges stations during the passage of Fay thus suggesting high rainfall rates were spatially generalized.

For the event that occurred in the late morning on the 05/06/09 (case IIIa), cross sections for reflectivity (Fig.7b) display a less uniform pattern than for tropical storm Fay (Fig. 7a) and a higher vertical extend from $2-4.5-\mathrm{km}$. The event covers a wide area along the $\mathrm{E}-\mathrm{W}$ direction while more scattered along the S-N direction. With an operational threshold of $10 \mathrm{~mm} / \mathrm{h}$ to distinguish stratiform from convective events, rain-rate profiles show several convective cells embedded within a region of moderate rainfall 

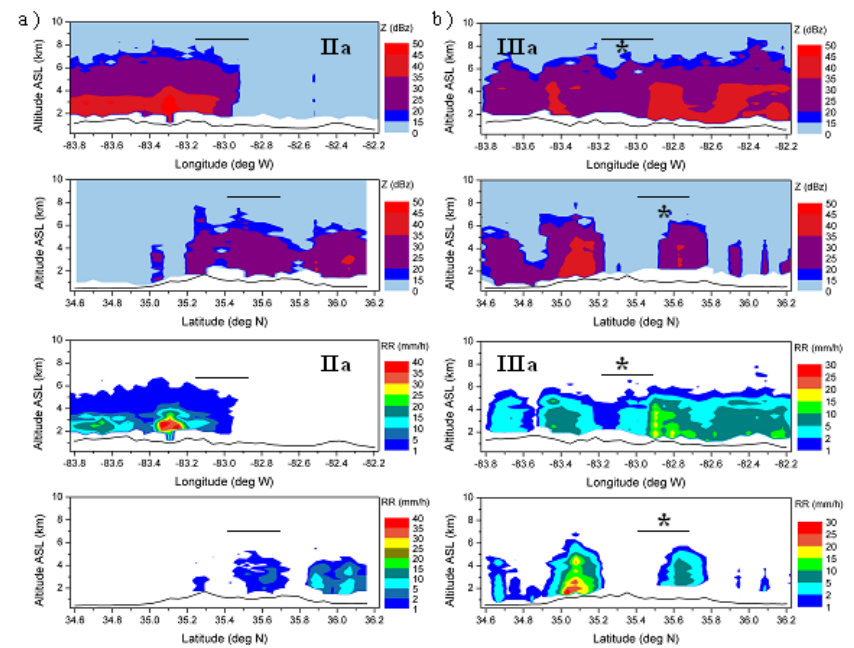

Fig. 7. Cross section of reflectivity (Z) and rain rate estimates (RR) from TRMM 2A25: (a) At approximately 21:26 UTC on 08/26/08 (tropical storm Fay) and corresponding to the situation IIa. (b) At approximately 13:21 UTC on 05/06/09 and corresponding to the situation IIIa. Horizontal bars indicate the approximate location of the GSMNP rain gauge network (RG0XX-RG1XX). The star indicates the approximate location of RG100-101-102-104-109. Locations of the cross sections are reported in Fig. 1.

$(\mathrm{RR}<5 \mathrm{~mm} / \mathrm{h})$. The regions of more intense convective activity ( $R R \approx 20-30 \mathrm{~mm} / \mathrm{h}$ ) were observed outside the geographical domain of the rain gauge network, but a convective core of lower intensity (symbol * in Fig. 7b) was found in the vicinity of five rain gauges installed along the Cataloochee divide (RG100-101-102-104-109: Fig. 1). The TRMM retrieved rain rates were of moderate to high intensity $(\mathrm{RR}>7 \mathrm{~mm} / \mathrm{h})$ while the corresponding rain gauges reported significantly lower rain-rates $(R R<7 \mathrm{~mm} / \mathrm{h})$ for the same period. It is interesting to note that even if classified as stratiform, TRMM PR reflectivity profiles and rain rate cross-sections suggest the presence of shallow convection embedded within a larger stratiform rain domain (Fig. 6d and Fig. 7b). Another way to consider TRMM PR/RG comparison is to focus on the TRMM-RG rain-rate probability density functions (PDF) for the five categories (I-II-IIIIV-V) previously defined (Fig. 8). For cases I-II-III (rain simultaneously retrieved by TRMM and measured by the rain gauges), comparable PDFs are obtained for TRMM and rain gauge rain-rates (Fig. 8a), while differences are pronounced for low $(\mathrm{RR}<1 \mathrm{~mm} / \mathrm{h})$ and high $(\mathrm{RR}>7 \mathrm{~mm} / \mathrm{h})$ rainrates (Fig. 8b) for case II, and for low (RR $<1 \mathrm{~mm} / \mathrm{h})$ and intermediate rain rates $(2 \mathrm{~mm} / \mathrm{h}<\mathrm{RR}<5 \mathrm{~mm} / \mathrm{h})($ Fig. $8 \mathrm{c})$ for case III. As expected, most important differences are found for cases IIa (Fig. 8d) and IIIa (Fig. 8e) with severe rain-rate underestimation by TRMM PR in the case of tropical storm Fay (Fig. 8d) or the difficulty for the rain gauges to fully capture convective cores embedded within stratiform events (Fig. 8e). Finally, when rain is either retrieved by TRMM
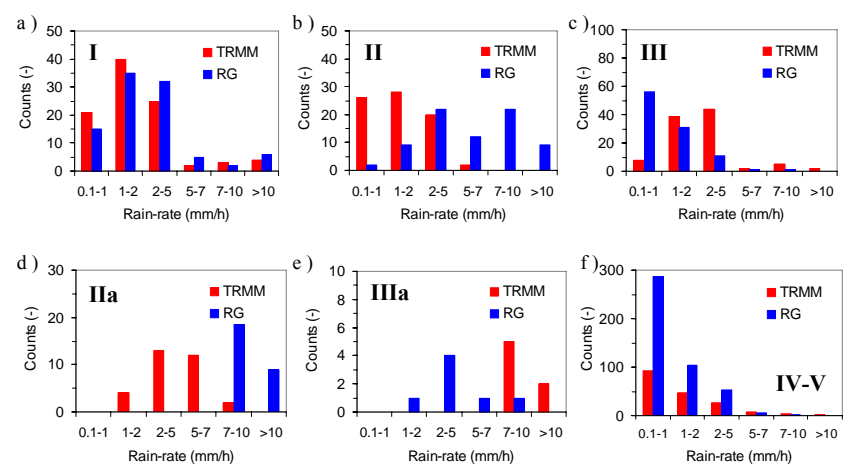

Fig. 8. TRMM-RG records repartition as a function of rain-rate and following to the TRMM-RG classification into five categories: (a) I (95). (b) II (76). (c) III (100). (d) IIa (31). (e) IIIa (7). (f) IV (180) and V (448).

or by the rain gauges, but not simultaneously (Classes IV$\mathrm{V})$, the larger PDF differences are in the low to intermediate rain-rate regime ( $R R<5 \mathrm{~mm} / \mathrm{h}$, Fig. $8 \mathrm{f})$. In addition to known challenges with regard to the retrieval of light rainfall such as PR low sensitivity and rain gauge performance for instance, we note that other aspects mentioned earlier can also explain those differences such as localized convective events, presence of summertime fog/low level clouds, snowfall, and wintertime delayed snow melting events detected by one or the other TRMM/RG.

\section{Surface rain rate estimation using a 1-D microphysical model (Prat and Barros, 2007a, b)}

Next, we ask the question of what would be the family of appropriate Z-R relationships to improve the overall performance of TRMM PR products in the region of study. For this purpose, we rely on a microphysical model to derive surface rain rate intensities from TRMM PR 2A25 corrected reflectivity. The microphysical model used here (Prat and Barros, 2007a, b) uses a spectral bin decomposition with explicit representation of drop coalescence and breakup processes, and it was previously used for the estimation of surface rain rates using vertically pointing radar data (Prat et al., 2008; Prat and Barros, 2009a) or TRMM PR 2A25 data (Prat and Barros, 2009b). The same methodology to derive surface rain rates using TRMM PR 2A25 corrected reflectivity (Zcorr) as top boundary condition for the model is adopted here. The strategy is as follows: (1) - only TRMM records with nonnull surface rain rates are selected; (2) - the corresponding corrected reflectivity (Zcorr) is extracted at $500 \mathrm{~m}$ below the $0^{\circ} \mathrm{C}$ isotherm to avoid the presence of ice phase; (3) - the reflectivity is converted into an exponential drop size distribution (DSD) to specify the top boundary condition:

$N(D)=\quad N_{0} \exp (-\Lambda D)$ 

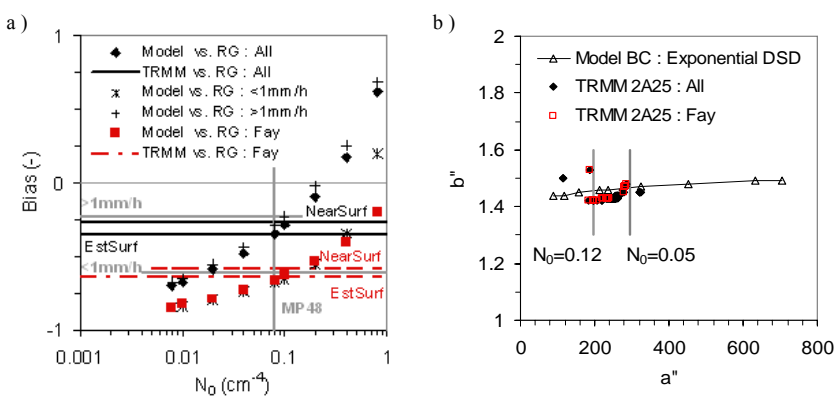

Fig. 9. Model/TRMM/RG comparison: (a) Bias between modeled and 10-min rain gauge rain intensity as a function of $\mathrm{N}_{0}$ for the period 06/01/08-05/15/09 and for tropical storm Fay on 08/26/08. For the period 06/01/08-05/15/09, TRMM near surface rain-rates are divided into subcategories ( $R R>1 \mathrm{~mm} / \mathrm{h}$ and $\mathrm{RR}<1 \mathrm{~mm} / \mathrm{h}$ ). (b) Coefficients $\left(a^{\prime \prime}, b^{\prime \prime}\right)$ of the Z-R relationships retrieved from TRMM 2A25 (at point D: see Iguchi et al. 2000 for definition) for the period 06/01/08-05/15/09 and tropical storm Fay, and for the exponential DSDs used as boundary condition in the 1-D microphysical model.

With $\mathrm{N}(\mathrm{D})$ and $\mathrm{N}_{0}$ are in $\left[\mathrm{cm}^{-4}\right]$ and the slope $\Lambda$ is in $\left[\mathrm{cm}^{-1}\right]$. Sensitivity analysis was performed using various values for the constant $\mathrm{N}_{0}$ ranging from $0.008-$ to $0.8-\mathrm{cm}^{-4}$, along with the original Marshall-Palmer (1948: MP48) value of $\mathrm{N}_{0}=0.08 \mathrm{~cm}^{-4}$. Regardless the value of the reflectivity factor (Zcorr), the fraction of small drops increases with increasing value of $\mathrm{N}_{0}$. Finally, the DSD is used as a boundary condition for the microphysical model.

Simulations with the 1-D-model are conducted for $15 \mathrm{~min}$ and the dynamic height of the vertical column is determined based on the location of the freezing level $\left(0^{\circ} \mathrm{C}\right) \mathrm{re}-$ trieved from TRMM $2 \mathrm{~A} 25$ at each time step. For all simulations, the time step is $\Delta t=1 \mathrm{~s}$ with a $\Delta \mathrm{z}=10 \mathrm{~m}$ vertical resolution (Prat and Barros, 2009b). An intercomparison of Model/TRMM/RG rain rates for the complete period of study (06/01/08-05/15/09) and for a single overpass corresponding to tropical storm Fay (08/26/08) shows that computed biases between TRMM 2A25 rain rates (near surface rain rate and estimated surface rain rate) correspond to an exponential DSD with coefficient $\mathrm{N}_{0}$ ranging from the classical MP48 value of $\mathrm{N}_{0}=0.08 \mathrm{~cm}^{-4}$ up to $0.12 \mathrm{~cm}^{-4}$ (Fig. 9a). This result is consistent with the values of coefficients $\left(a^{\prime \prime}, b^{\prime \prime}: Z=a^{\prime \prime} R^{b^{\prime \prime}}\right)$ used to derive rain-rates from corrected reflectivities in the TRMM PR 2A25 algorithm at level D corresponding to the level where hydrometeors are supposed to be fully melted (see Iguchi et al., 2000 for definition) (Fig. 9b). A comparison of model surface rain rates against rain gauge rates indicates that bias increases with increasing $\mathrm{N}_{0}$ (i.e. with increasing population of small drops). Furthermore, for the entire period of study 06/01/08-05/15/09 taken as a whole, the optimal value of $\mathrm{N}_{0}$ is such that the bias would vanish (Bias = 0: Eq. 1) for $\mathrm{N}_{0} \approx 0.22-0.25-\mathrm{cm}^{-4}$ which again is much higher than MP's $\mathrm{N}_{0}=0.08 \mathrm{~cm}^{-4}$ (Marshall and Palmer, 1948) (Fig. 9a), and well outside of the range $\left(0.05 \mathrm{~cm}^{-4}<\mathrm{N}_{0}<0.12 \mathrm{~cm}^{-4}\right)$ used in TRMM PR 2A25 algorithm (Fig. 9b). When light rainfall $(\mathrm{RR}<1 \mathrm{~mm} / \mathrm{h})$ is considered separately, TRMM PR rain-rates exhibit a negative bias (Bias $=-0.60$ : Eq. 1) that would vanish for a higher value of $\mathrm{N}_{0}\left(\mathrm{~N}_{0} \approx 0.6 \mathrm{~cm}^{-4}\right)$ and outside the range $\left(0.05 \mathrm{~cm}^{-4}<\mathrm{N}_{0}<0.12 \mathrm{~cm}^{-4}\right)$ mentioned above. This numerical result is consistent with observations that report an underestimation of light rainfall in mountainous regions due to the PR low sensitivity (Barros et al., 2000, Lang and Barros, 2002). The Gamma DSD with a fixed exponent ( $\mu=3$ : Iguchi et al., 2000) used in the TRMM PR algorithm implies a DSD depleted of small drops as compared with the exponential DSD ( $\mu=0$ : Eq. 2 ), which might explain TRMM/RG differences observed as suggested by the TRMM/Model comparison.

For tropical storm Fay (08/26/08), a minimum bias Model/RG is found for $\mathrm{N}_{0} \approx 1.0 \mathrm{~cm}^{-4}$ which is more than 10 -fold the default value $\mathrm{N}_{0}=0.08 \mathrm{~cm}^{-4}$ (Fig. 9a). Indeed this indicates that in order to achieve a better agreement between TRMM surface rain rates (near surface or estimated) and rain gauge point measurements, an increase of one order of magnitude in the number of small drops is apparently needed regardless of the value of the measured reflectivity. These simulation results are in good agreement with DSD observations that report a high concentration of small and/or midsize drops in the case of tropical storms (Tokay et al., 2008). In addition, Tokay et al. (2008) found that larger drops rarely exceeded $4 \mathrm{~mm}$ which is consistent with higher values of $\mathrm{N}_{0}$ as obtained here in the case of tropical storm Fay $\left(\mathrm{N}_{0} \approx 0.7 \mathrm{~cm}^{-4}\right)$ (Fig. 9a). Furthermore, Ulbrich and Lee (2002) reported similar DSD observations during tropical storm Helene in 2000. Substantial differences were found between pre-storm conditions and during the passage of the tropical storm with a narrower DSD observed during the passage of the tropical storm (Ulbrich and Lee, 2002). From a microphysical perspective, the implication is that, the higher concentration of small drops will lead to enhanced drop coalescence which was found to be the dominant mechanism by Prat and Barros, 2009a for rain rates $\mathrm{RR}<20 \mathrm{~mm} / \mathrm{h}$, the most frequent case in the data studied here (Fig. 8). Furthermore, numerical results obtained for tropical storm Fay confirm that DSD models used for tropical storms overestimate the number of large drops (Maeso et al., 2005). Finally, this exercise further confirms the benefit of using a microphysical model in order to derive surface rain rate explicitly from reflectivity measurements (Prat et al., 2008; Prat and Barros, 2009a, b).

\section{Summary and conclusions}

In this work we presented precipitation observations obtained with a newly deployed rain gauge network in the southern Appalachians. A comparison of TRMM PR 2A25 estimates was performed against 20 rain gauges for a one year period from summer 2008 to spring 2009. In addition, results 
obtained with a 1-D microphysical model were performed in order to derive surface rain rate from TRMM reflectivity measurements. The main findings can be summarized as follows:

1. Rain gauge observations display very large differences in rain accumulation with up to a 3 -fold increase in the daily average for rain gauges over a distance of less than $8 \mathrm{~km}$. Rain accumulation was found to increase with increasing elevation, but more consistent behavior was found with respect to the specific location of the rain gauges with regard to regional hydrometeorology: rainfall accumulation increases in the NE direction consistent with the track of SWesterly events as they interact with the mountain ridges. As longer observational records become available, it will be possible to separate the contribution of large scale weather systems (such as tropical storms) and localized convective activity.

2. The comparison of TRMM PR 2 A25 precipitation products and rain gauge observations points to an overall bias of $-27 \%$ between TRMM PR 2A25 near surface rain rate and 10-min gauge rate for the complete one year of study (06/01/08-05/15/09). However, differences were found to vary greatly considering particular rain events such as in the case of tropical storm Fay $(08 / 26 / 08)$ where a relative bias of $-59 \%$ was observed. About 50\% (448) of all overpasses correspond to instances when rainfall was detected at the rain gauges only, and the remaining 20\% (180) by TRMM only. In both cases, the mismatch corresponds to low and moderate rainfall regimes with a large proportion of misses in the light rainfall range $0.1-1 \mathrm{~mm} / \mathrm{h}$. Longer term records combined with ground based radar products could help determining if this mismatch is due to a limited performance of the rain gauge network or to TRMM PR sensitivity.

3. Model/TRMM/RG intercomparison showed that an improvement in the skill of TRMM 2A25 products can be obtained by changing the parameters of the (exponential) DSD derived from the TRMM corrected reflectivity factor. Specifically, model simulations suggest a higher concentration of small and/or midsize drops in the case of tropical storms, and consequently for summertime convective events generally. The same is true for light rainfall.

Finally, this work is a first step on a longer-term approach that consists in quantifying spatial-temporal rainfall variations in remote mountainous area and will be later completed in order to derive longer-term trends throughout the lifespan of the GSMNP rain gauge network that has been extended to 33 rain gauge stations in summer 2009. In addition, future work will consist in the comparison of rain gauge and TRMM PR products with next generation QPE (Q2) products.
Acknowledgements. This research was supported in part by grant NASA NNX07AK40G with the second author. The authors are grateful to Douglas Miller, Anna Wilson, Gregory Cutrell, Daniel Martin, Wes Groetsema, Melissa Talley, Aaron Woodward from UNCA, Do-Hyuk Kang and Xiaoming Sun that participated in the installation, maintenance, and data collection of the GSMNP rain gauge network. The authors are grateful to Paul Super and Susan Sachs from the National Park Service (NPS) for their invaluable help. The authors express their gratitude to two anonymous reviewers for their valuable and constructive comments.

Edited by: S. C. Michaelides

Reviewed by: two anonymous referees

\section{References}

Amitai, E., Marks, D. A., Wolff, D. B., Silberstein, D. S., Fisher, B. L., and Pippitt, J. L.: Evaluation of radar rainfall products: Lessons learned from the NASA TRMM validation program in Florida. J. Atmos. Ocean. Tech., 23, 1492-1505, 2006.

Barros, A. P., Joshi, M., Putkonen, J., and Burbank, D. W.: A study of the 1999 monsoon rainfall in a mountainous region in central Nepal using TRMM products and rain gauge observations, Geophys. Res. Lett., 27(22), 3683-3686, 2000.

Barros, A. P., Prat, O. P., Shrestha, P., Testik, F. Y., and Bliven, L. F.: Revisiting Low and List (1982): Evaluation of raindrop collision parameterizations using laboratory observations and modeling, J. Atmos. Sci., 65, 2983-2993, 2008.

Barros, A. P. and Tao, K.: A space-filling algorithm to extrapolate narrow-swath instantaneous TRMM microwave rain-rate estimates using thermal IR imagery, J. Atmos. Ocean. Tech., 25, 1901-1920, 2008.

Franchito, S. H., Brahmananda Rao, V., Vasques, A. C., Santo, C. M. E., and Conforte, J. C.: Validation of TRMM precipitation radar monthly rainfall estimates over Brazil, J. Geophys. Res., 114, D02105, doi:10.1029/2007JD009580, 2009.

Iguchi, T., Kozu, T., Meneghini, R., Awaka, J., and Okamato, K.: Rain-profiling algorithm for the TRMM precipitation radar, J. Appl. Meteorol., 39, 2038-2052, 2000.

Lamptey, B. L.: Comparison of gridded multisatellite rainfall estimates with gridded gauge rainfall over West Africa. J. Appl. Meteorol. Clim., 47, 185-205, 2008.

Lang, J. L. and Barros, A. P.: An investigation of the onsets of the 1999 and 2000 monsoons in central Nepal, Mon. Weather Rev., 130, 1299-1316, 2002.

Maeso, J., Bringi, V. N., Cruz-Pol, S., and Chandrasekar, V.: DSD characterization and computations of expected reflectivity using data from a two-dimensional video disdrometer deployed in a tropical environment. Proc. Int. Geoscience and Remote Sensing Symp., Seoul, South Korea. IEEE, 7, 5073-5076, 2005.

Marks, D. A., Wolff, D. B., Silberstein, D. S., Tokay, A., Pippitt, J. L., and Wang, J. X.: Availability of high-quality TRMM ground validation data from Kwajalein, RMI: A practical application of the relative calibration adjustment technique, J. Atmos. Ocean. Tech., 26, 413-429, 2009.

Marshall, J. S. and Palmer, W. M.: The distribution of raindrops with size, J. Meteorol., 5, 165-166, 1948.

Meneghini, R., Iguchi, T., Kozu, T., Liao, L., Okamato, K., Jones, J. A., and Kwiatkowski, J.: Use of the surface reference tech- 
nique for path attenuation estimates from the TRMM precipitation radar, J. Appl. Meteorol., 39, 2053-2070, 2000.

Prat, O. P. and Barros, A. P.: A robust numerical solution of the stochastic collection-breakup equation for warm rain, J. Appl. Meteorol. Clim., 46, 1480-1497, 2007a.

Prat, O. P. and Barros, A. P.: Exploring the use of a column model for the characterization of microphysical processes in warm rain: Results from a homogeneous rainshaft model, Adv. Geosci., 10, 145-152, 2007b, http://www.adv-geosci.net/10/145/2007/.

Prat, O. P. and Barros, A. P.: Ground observations to characterize the spatial gradients and vertical structure of orographic precipitation - Experiments in the inner region of the Great Smoky Mountains, J. Hydrol., under review, 2009a.

Prat, O. P. and Barros, A. P.: Exploring the transient behavior of Z-R relationships: Implications for radar rainfall estimation, J. Appl. Meteorol. Clim., 48, 2127-2143, 2009b.

Prat, O. P., Barros, A. P., and Williams, C. R.: An intercomparison of model simulations and VPR estimates of the vertical structure of warm stratiform rainfall during TWP-ICE, J. Appl. Meteorol. Clim., 47, 2797-2815, 2008.

Robinson, M., Kulie, M. S., Silberstein, D. S., Marks, D. A., Wolff, D. B., Amitai, E., Ferrier, B. S., Fisher, B. L., and Wang, J.: Evolving improvements to TRMM ground validation rainfall estimates, Phys. Chem. Earth Pt. B, 25, 971-976, 2000.
Tokay, A., Bashor, P. G., Habib, E., and Kasparis, T.: Raindrop size distribution measurements in tropical cyclones, Mon. Weather Rev., 136, 1669-1685, 2008.

Ulbrich, C. W. and Lee, L. G.: Rainfall characteristics associated with the remnants of Tropical Storm Helene in upstate South Carolina, Weather Forecast., 17, 1257-1267, 2002.

Vila, D. A., De Goncalves, L. G. G., Toll, D. L., and Rozante, J. R.: Statistical evaluation of combined daily gauge observations and rainfall satellite estimates over continental South America, J. Hydrometeorol., 10, 533-543, 2009.

Wang, J., Fisher, B. L., and Wolff, D. B.: Estimating rain rates from tipping-bucket rain gauge measurements, J. Atmos. Ocean. Tech., 25, 43-56, 2008.

Wolff, D. B., Marks, D. A., Amitai, E., Silberstein, D. S., Fisher, B. L., Tokay, A., Wang, J., and Pippitt, J. L.: Ground validation for the Tropical Rainfall Measuring Mission (TRMM), J. Atmos. Ocean. Tech.., 22, 365-380, 2005.

Zhou, T., Yu, R., Chen, H., Dai, A., and Pan, Y.: Summer precipitation frequency, intensity, and diurnal cycle over China: A comparison of satellite data with rain gauge observations, J. Climate, 21, 3997-4010, 2008. 